\title{
Implementación de un observatorio anticorrupción y transparencia en Bolivia
}

\author{
Implementation of an anti-corruption and transparency observatory in Bolivia
}

Implementação de um observatório anticorrupção e transparência na Bolívia

Artículo recibido en enero 2019

Arbitrado en marzo 2019

Publicado en abril 2019

\section{Marisabel Gonzáles Vásquez} abog.gonzales@hotmail.com

Universidad Autónoma Tomás Frías, Bolivia
RESUMEN

ABSTRACT

RESUMO

A corrupção existiu com o passar do tempo, desde a criação da humanidade, quando se organizaram em pequenas aldeias, depois em cidades e estados rurais. Para entendê-lo, vários fatores como realidade social, educação e / ou doutrinação, oportunidade, América e corrupção devem ser compreendidos. Assim, pode-se indicar que não existe uma razão única para ser vítima da corrupção atual. O objetivo principal do estudo foi a implementação de um Observatório Anticorrupção na Bolívia. É uma investigação teórica do tipo JurídicoHistórico, foi utilizada a técnica de análise documental, os métodos utilizados foram indutivos, históricos e estruturais. Como resultado, o desenvolvimento de um meio de controle proposto para o Observatório Boliviano Anticorrupção e Transparência Centro "COATBOL. Por fim, foi gerada a proposta de implantação de um observatório anticorrupção que permitirá o acesso direto a dados e estatísticas sobre corrupção na Bolívia.

Palavras-chave: Corrupção; observatório anticorrupção; direito Comparado, direito penal, Bolívia 


\section{INTRODUCCIÓN}

La corrupción Carl Friedrich la plantea como el comportamiento desviado, asociado con una motivación particular, que es la del beneficio particular a costa del público. Moreno (1993). Para transparencia internacional es un tanto más sencillo; define a la misma como el mal uso del poder encomendado para obtener beneficios particulares, Senturia (1993).

La corrupción ha existido desde el mundo antiguo hasta la actualidad, desde la creación o asociación de la humanidad en pequeñas aldeas, luego ciudades y estados países. Siempre que exista un conjunto de personas asociadas bajo una administración se abrirán puertas para que algunas personas, impulsadas por el deseo de lo material y la riqueza, traicionen a sus pares y representados, Senturia (1993).

La corrupción no es una enfermedad o epidemia, aunque en algunos casos se refieren a ella como tales respecto a la sociedad. Por tanto, ¿cómo puedo combatirla? Para poder combatirla, primero hay que entender que existen factores que deben de ser tomados en cuenta, uno de ellos tiene que ver con Realidad social no todas las sociedades y culturas son iguales. Los Aspectos demográficos, Económicos y Culturales toman gran importancia respecto a la opinión general de dicha sociedad respecto a los actos que podemos considerar como "Corrupción", en esto basamos el ánimo que podrían tener las personas en cuestión a la hora de cometer dichos actos. Por mencionar algunos, en sociedades como las asiáticas donde el honor y la honra son los más valiosos valores, un acto de corrupción puede ser penado hasta con la muerte a diferencia de Occidente donde solo se considera un robo con posible agravante y la pena no es lo suficientemente severa.

El segundo factor seria la educación y adoctrinamiento se debe enseñar a no robar, no solo obviarlo. Muchas sociedades concentran su educación tan solo en lo bueno y positivo obviando algo tan esencial como la clásica frase que dice "la vida tiene dos sabores, uno dulce y otro amargo, lo bueno y lo malo".

No es lo mismo enseñar honradez y enseñar a no robar, y como tal a no ser corruptos. A todos nos dicen que robar es malo, pero no entramos mucho en el análisis. El sistema educativo de muchas sociedades en general solo prepara a los jóvenes para una vida de trabajo, pero ¿los prepara para trabajar por una vida? Una vida de honor, sacrificio, orgullo y admiración. ¿Los valores se trabajan lo suficiente?

El tercer factor oportunidad no existe la misma dificultad para ser corruptos en todas las sociedades. De acuerdo a cada sociedad existen oficinas, agencias, métodos, controles y obstáculos que no permiten o por lo menos obligan a los funcionarios públicos a pensarlo dos veces antes de cometer algún acto corrupto. Sin embargo, las sociedades en las cuales se descuida mucho esta situación tienen como 
consecuencia la existencia de fruto del caos, fruto de la peor desgracia que puede acarrear esta situación: "la aceptación".

El último factor, América y la corrupción muy pocas acciones se han tomado para poder contrarrestar el problema y los planes, tratados e iniciativas que se han realizado no han llegado a tener el alcance suficiente para poder ser consideradas significativas. La Organización de Estados Americanos "OEA", ha sido la principal impulsora de la lucha contra la corrupción en el continente y sigue en la pelea sin desistir en el intento. Se puede indicar que no existe una sola causal, o que no existe un solo motivo para que los ciudadanos no sean víctimas de la ola de corrupción actual, pero sí pudiera tan solo resumir todas las ideas en un solo pensamiento.

El estudio determina la falta de compromiso de los gobiernos de turnos para combatir la corrupción en Bolivia partiendo de la necesita de otra opción, se tuvo como objeto de estudio la corrupción y la falta de un observatorio de anticorrupción y transparencia en Bolivia. El campo de acción es el Derecho Penal, enfocado a la problemática de la prevención de corrupción en el Estado Plurinacional de Bolivia. Como objetivo principal se planteó la implementación de un Observatorio Anticorrupción en Bolivia.

La justificación del estudio parte de dos vertientes una está relacionada Relevancia Científica la cual constituye un aporte porque permitirá crear un centro de observación anticorrupción y de transparencia en Bolivia; la segunda está ligada a la Relevancia Social la cual constituirá un aporte social porque permite que la sociedad boliviana poder acceder a la información y es un organismo que se le suma para denunciar aquellos hechos considerados fuera de norma.

\section{Marco histórico}

Corrupción en la Antigüedad. Para Aristóteles, la corrupción aparece como lo opuesto a la virtud, lo que equivale, para el estagirita, a lo antinatural. De este modo, el gobierno no es el resultado de la relación entre Ciudadanos como sujetos libres y racionales. Así que, son las formas específicas principales de desvirtuar el sentido de la política.

Por lo tanto, Aristóteles señala la corrupción como el bien mayor y está relacionado con la posibilidad de ser sujeto cabal de la vida pública. Así que, todas las comunidades pretenden como fin superior la que es superior y comprende a las demás. Esta es la que se llama ciudad y comunidad cívica, León (1996).

La corrupción sería la desvirtuación del bien mayor, esto es de la vida pública, porque ello compromete el sentido de la existencia propiamente de los seres humanos. Así lo público es lo social y subjetivamente más evolucionado, pero esa importancia a su vez es resultado de que las posibilidades racionales aparezcan 
jerarquizadas por encima de los apetitos. Pero el ser humano posee, y es, dice Aristóteles, más primitiva una tendencia a lo egoísta.

Corrupción Contemporánea. En la actualidad se hace evidente que el desarrollo de las relaciones mercantiles es la dinámica universal de intercambio social en el mundo. La expresión "globalización" que se difunde en la década del 1990, deriva, sobre de dos fenómenos: la implosión de la URSS y la eclosión de INTERNET. Sin embargo, la globalización es, en lo sustantivo un peldaño más de un largo proceso histórico-objetivo de mundialización del Mercado.

A medida que el mercado se ha universalizado, el dinero, además de ser imprescindible para adquirir los bienes para la satisfacción de distintas necesidades, ha ido emergiendo como el sine que non para que cada uno pueda ser reconocido como ser social. De esta manera, la vivencia cotidiana del dinero como pauta decisiva para la vida, hace que cada uno interiorice al dinero como su posibilidad de ser social, esto es de ser reconocimiento como sujeto, León (1996). De este modo, la interiorización del dinero se ha convertido en un valor predominante de la sociedad contemporánea.

\section{Medidas anticorrupción adoptadas en Bolivia}

El 7 de febrero de 2009 Bolivia promulgó la Constitución Política del Estado (CPE) del nuevo Estado Plurinacional de Bolivia. Este contiene disposiciones relativas y conexas a los conflictos de intereses en el desempeño de la función pública.

Se puede decir que, Bolivia está en proceso de elaboración y aprobación de un Código de Ética marco que desarrolla los nuevos principios y valores aplicables a la función pública y el funcionamiento del Estado, adoptados en la nueva Constitución Política del Estado en el artículo 8, (Bouer, 2009, p. 30)

Este documento será el marco-guía bajo el cual todas las entidades públicas del sector público deberán aprobar sus propios códigos de conducta ética. Contiene, además de los valores y principios de conducta ética, parámetros y requisitos mínimos de contenido de los códigos de ética, mecanismos de evaluación, y plazos para la implementación de estos, (Bouer, 2009, p. 30)

Estos nuevos instrumentos legales reestructurarán el sistema de declaraciones de bienes y rentas con el objetivo de darle mayor importancia como herramienta para prevenir la corrupción a través de la detección o identificación de enriquecimiento ilícito y otros delitos En este sentido, el Ministerio de Transparencia Institucional y Lucha contra la Corrupción está gestionando la participación del país en la iniciativa STAR (Stolen Asset Recovery Inititiative) del Banco Mundial y las Naciones Unidas 


\section{MÉTODO}

La investigación fue de carácter teórico, pues se consultaron documentos, leyes, reformas, proyectos y tratados de la legislación boliviana. Los tipos de investigación usado en el desarrollo de estudio fueron Histórico Jurídico porque se analizó la evolución de las normas, proyectos y medidas adoptadas en Bolivia para la transparencia y lucha contra la corrupción; Jurídico propositivo porque el trabajo en sí, se basa en la proposición de la creación del centro observatorio. Jurídico descriptivo, porque mediante esta investigación se identificó la situación actual en cuanto a corrupción en Bolivia. La técnica de investigación que se usó fue documental y los métodos de investigación empleados fueron inductivo, porque mediante el análisis de varios puntos respecto a la corrupción, se planteó llegar a algo específico como es el centro observatorio en Bolivia, histórico, porque realizó un análisis detallado de la evolución histórico de la corrupción y la anticorrupción. Por último, estructural, porque se trabajó en un tema de fondo, estructural de la sociedad como es la corrupción.

\section{RESULTADO Y DISCUSIÓN}

\section{Medio de control planteado del Centro Observatorio Anticorrupción y de Transparencia Boliviano "COATBOL"}

Se desarrolló el medio de control planteado del centro Observatorio Anticorrupción y de Transparencia Boliviano, partiendo desde la identificación del problema, seguido de las pautas necesarias para su implementación, formalismos legales, actas de constitución, visión, misión, y objetivos del centro. Tomando como base los objetivos de la investigación.

\section{La corrupción}

El concepto de corrupción es considerado complicado, dado a que se señala tres grandes problemas que explican esta dificultad: el primero es que existen muchos problemas relacionados con la corrupción que se suelen confundir y tratar indistintamente, como el fraude, el abuso de poder o el robo, entre otros. Un segundo problema es que hay diferencias importantes entre la corrupción reconocida por la normatividad oficial, los actos de corrupción que no están reconocidos por la ley, pero que afectan al interés público, y los actos que, según la población, son percibidos como actos corruptos. $Y$ el tercero es que hay diferencias entre las distintas sociedades en la manera en que usan la palabra 'corrupción', Gardiner (2005). 
Cabe destacar, que a pesar de las discusiones y debates teóricos que se han generado no se cuestionan los elementos fundamentales en la que está sumergido el concepto de corrupción. Así que, de implícita o explícitamente en la gran mayoría de las definiciones, son cuatro: i) la presencia de uno o más actores, sean estos individuales o colectivos; ii) una motivación que desvía la acción de los actores de sus funciones originales; iii) una conducta estratégica que permite burlar los mecanismos de control existentes; y iv) la existencia de recursos que son desviados de su finalidad original para satisfacer las motivaciones corruptas mencionadas.

\section{Centro Observatorio Anticorrupción y de Transparencia Boliviano "COATBOL"}

\section{Acta de fundación}

Se elaboró y suscribió un acta con la finalidad de considerar la creación de una Fundación Privada, sin fines de lucro, bajo el denominativo de Centro Observatorio Anticorrupción y de Transparencia Boliviano cuya sigla es "COATBOL"; con el siguiente Orden del Día:

a) Constitución y Fundación del Centro Observatorio Anticorrupción y de Transparencia Boliviano cuya sigla es "COATBOL".

b) Nominación de las personas encargadas de la elaboración del Estatuto y Reglamento Interno de la Fundación.

\section{Acta de elección del directorio}

Se elaboró y suscribió esta acta a fin de considerar la creación de una Fundación, sin fines de lucro, bajo el denominativo de Centro Observatorio Anticorrupción y de Transparencia Boliviano cuya sigla es "COATBOL"; con el siguiente Orden del Día:

a) Designación del Directorio.

b) Juramento y posesión del Directorio.

De este modo quedó establecido que esta Directiva tiene la obligación de obtener su personalidad Jurídica, al efecto el Directorio decidió iniciar los trámites correspondientes para lo cual estableció que el Directorio gozara de la facultad de otorgar el poder suficiente para que la persona designada por el Directorio pueda tramitar lo más antes posible la Personería Jurídica de la Institución. 


\section{Régimen disciplinario}

\section{Estatuto Orgánico}

Se estableció un estatuto orgánico para el Centro Observatorio Anticorrupción y de Transparencia Boliviano el cual es nombrado por sus siglas COATBOL. Este está compuesto por cinco títulos y a su vez se encuentra subdivido por capítulos.

En el primer título contempla las disposiciones generales el cual incluye un capítulo donde especifica los siguientes aspectos: la denominación y naturaleza, domicilio, duración, visión, misión y finalidades, objetivos, valores y aplicación

En el segundo título se hace referencia al patrimonio y fuentes de sus recursos. y se desarrolla en dos capítulos. El capítulo uno, especifica en tres artículos el patrimonio del COATBOL, responsabilidad, destino del patrimonio y naturaleza no lucrativa. El capítulo dos, desarrolla en dos artículos, las fuentes de sus recursos y la consolidación patrimonial.

En el tercer título se desarrolla la organización y órganos de administración del Centro Observatorio Anticorrupción y de Transparencia Boliviano "COATBOL" a través de cuatro capítulos.

El capítulo uno se amplía la estructura organizativa, el cual está conformado por el principio de autoridad y los niveles orgánicos.

El siguiente capítulo plantea el nivel deliberante de los Asociados Fundadores, Nuevos Asociados del COATBOL.

El tercer capítulo se señala todo lo referente al nivel deliberante de la Asamblea de asociados, el mismo, constituye la máxima autoridad jerárquica. En el cuarto capítulo, se desarrolla el nivel directivo del COATBOL y sus miembros. Y en el último capítulo, se desarrolla de igual manera el nivel directivo de COATBOL, pero centradas en sus autoridades, como los podría ser la presidencia, vicepresidencia, secretario general, secretario de hacienda, directores del directorio

En el cuarto título se despliega la información sobre la reforma y disolución, dividido en dos capítulos, la primera, en la reforma del estatuto y sus reglamentos, y el segundo, en la disolución del COATBOL

En el último título, se destacan las normas supletorias y la vigencia de los estatus mencionados, de esta forma el presente estatuto tendrá vigencia desde la fecha de su aprobación por la Asamblea de Asociados, reunida como acto fundacional, sin perjuicio de la tramitación del reconocimiento de personalidad jurídica conforme a ley. 


\section{Derecho comparado}

\section{Estructura Boliviana de lucha contra la corrupción}

\section{La Constitución Política del Estado}

La Constitución política del Estado de febrero de 2009 establece en Artículo 112, que los delitos cometidos por servidores públicos que atenten contra el patrimonio del Estado y causen grave daño económico, son imprescriptibles y no admiten régimen de inmunidad" (Constitución Política del Estado plurinacional de Bolivia, 2009).

\section{Agencias gubernamentales anticorrupción en Bolivia}

Ministerio de Transparencia Institucional y Lucha Contra la Corrupción

Con relación al funcionamiento, tras la aprobación de la Nueva Constitución Política del Estado mediante Referéndum del 25 de enero de 2009, a través del Decreto Supremo N.o 29.894 se creó el Ministerio de Transparencia Institucional y Lucha Contra la Corrupción. Así mismo, el Ministerio está organizado principalmente en dos grandes áreas: el Viceministerio de Prevención de la Corrupción, Promoción de Ética y Transparencia y el Viceministerio de Lucha Contra la Corrupción. El primero se halla enfocado en el aspecto preventivo y el otro en el aspecto investigativo y de control. A su vez, el trabajo operativo se realiza por medio de tres entes: Dirección General de Asuntos Jurídicos, Dirección General de Asuntos Administrativos y la Dirección General de Planificación, (Bouer 2009, p31).

\section{Funciones y competencias}

Las atribuciones del Ministerio de Transparencia Institucional y Lucha Contra la Corrupción, en el marco de las competencias asignadas al nivel central en la Constitución Política del Estado 6, se puede mencionar algunos:

a) Promover programas de capacitación ciudadana en las áreas de su competencia con especial énfasis en la formación de valores y códigos de ética.

b) Diseñar mecanismos de fortalecimiento y coordinación institucional, para la gestión con transparencia y lucha contra la corrupción.

c) Supervisar el cumplimiento de la obligación de los servidores públicos de rendir cuentas en todas las entidades públicas del país.

d) Coordinar la investigación, seguimiento y monitoreo de hechos y procesos judiciales contra la corrupción.

e) Verificar y trabajar por el cumplimiento de las convenciones y acuerdos internacionales sobre lucha contra la corrupción. 


\section{Contraloría general del Estado}

La Contraloría General del Estado está facultada para determinar indicios de responsabilidad administrativa, ejecutiva, civil y penal; tiene autonomía funcional, financiera, administrativa y organizativa. Por lo tanto, su ámbito de aplicación es el Control Externo Posterior. (Bouer, 2009, p 31).

La estructura organizativa de la Contraloría General del Estado cuenta con una Secretaría General y dos Gerencias principales, Gerencia de Declaración Jurada de Bienes y Rentas y la Gerencia Nacional de Auditoría Interna. Asimismo, cuenta con nueve Gerencias Departamentales, (Bouer, 2009, p. 32).

A nivel de prevención y control la Contraloría General del Estado ejerce el Control Externo Posterior, a través de auditorías y evaluaciones de las entidades públicas y de aquellas en las que el Estado tenga participación o interés económico. La Contraloría está facultada para determinar indicios de responsabilidad administrativa, ejecutiva, civil y penal. Por otro lado, en su calidad de Órgano Rector del Sistema de Control Gubernamental, la Contraloría General del Estado tiene la atribución de promover la implantación del control interno en las entidades del sector público. Asimismo, entre sus competencias se encuentra la de verificar el contenido de las Declaraciones de Bienes y Rentas, (Bouer, 2009, p. 33).

\section{Agencias gubernamentales anticorrupción Brasil}

\section{Contraloría General de la Unión}

La Contraloría General de la Unión (CGU) es el órgano de control del Gobierno Federal que depende directamente del presidente de la República. Es responsable de dar asistencia directa e inmediata al presidente de la República en los asuntos que, en el ámbito del Poder Ejecutivo, sean relativos a la defensa del patrimonio público y al aumento de la transparencia de la gestión por medio de las actividades de control interno, auditoría pública, corrección, prevención y combate a la corrupción y mediación, (Bouer 2009, p 34).

\section{Comisión de Ética Pública}

En el ámbito funcionamiento la Comisión de Ética pública fue creada en mayo de 1999 como órgano consultivo que depende directamente de la Presidencia de la República, y es responsable de la administración del Código de Ética de la Administración Pública Federal 


\section{Comisiones Sectoriales de Ética en el Poder}

Además de la Comisión de Ética Pública, existen 122 Comisiones Sectoriales de Ética en el Poder Ejecutivo Federal. Cada Comisión Sectorial está encargada de orientar y asesorar sobre la ética profesional del funcionario, en el trato con las personas y con el patrimonio público. A partir del año 2001 se establece que las Comisiones de Ética Sectoriales del Poder Ejecutivo Federal actuarán como elemento de enlace con la Comisión de Ética Pública, correspondiéndoles, en el ámbito de los respectivos órganos y entidades, los siguientes cometidos: supervisar la observancia del Código de Conducta de la Alta Administración Federal y poner en conocimiento de la Comisión de Ética Pública situaciones que puedan configurar incumplimiento de sus normas; promover la adopción de normas de conducta ética específicas para sus funcionarios y empleados

\section{Agencias gubernamentales anticorrupción Chile:}

\section{Contraloría General de la República}

En el ámbito de funcionamiento el órgano superior de fiscalización de la Administración del Estado, contemplado en la Constitución Política, goza de autonomía frente al Poder Ejecutivo y demás órganos públicos. Es esencialmente una entidad de control de legalidad de los actos de la Administración del Estado, que no está sometida al mando ni a la super vigilancia del Poder Ejecutivo ni del Congreso Nacional. (Bouer 2009 p46).

Comisión Asesora Presidencial para la Protección de los Derechos de las Personas

Esta comisión es un órgano dependiente de la Presidencia de la República creado en el año 2001. Su ámbito de acción se circunscribe a los órganos dependientes de la Administración Central del Estado (Bouer 2009 p49).

\section{Agencias gubernamentales anticorrupción Colombia}

\section{Programa Presidencial de Lucha Contra la Corrupción}

Este Programa es el responsable al interior de la Presidencia de la República de coordinar la implementación de las políticas gubernamentales orientadas a disminuir la corrupción en la Administración por el cual se crean las Consejerías y Programas Presidenciales en el Departamento Administrativo de la Presidencia de la República, (Bouer, 2009, p. 50). 


\section{Procuraduría General de la Nación}

La Procuraduría General de la Nación es la entidad que representa a los ciudadanos ante el Estado. Es el máximo organismo del Ministerio Público, conformado además por la Defensoría del Pueblo, y la Contraloría General de la República. En su calidad de sujeto procesal, la Procuraduría General de la Nación interviene ante las jurisdicciones Contencioso Administrativa, Constitucional y ante las diferentes instancias de las jurisdicciones; penal, penal militar, civil, ambiental, agrario, de familia, laboral, ante el Consejo Superior de la Judicatura y las autoridades administrativas y de policía, (Bouer, 2009, p. 68).

\section{Agencias gubernamentales anticorrupción Ecuador}

\section{Secretaría Nacional de Transparencia de Gestión}

Es creada mediante Decreto Presidencial N. ${ }^{\circ} 1511$ del 29 de diciembre de 2008, esta nueva Secretaría, adscripta a la Presidencia de la República y dotada de personalidad jurídica de derecho público, sustituye a la Secretaría Nacional Anticorrupción, que se suprimió después de la aprobación de la nueva Constitución política de Ecuador en septiembre de 2008. Entidad con competencia sobre las instituciones de la Administración Pública Central, inclusive en las instituciones autónomas que formen parte de ellas, (Bouer, 2009 p. 57).

Consejo de Participación Ciudadana y Control Social

El Consejo de Participación Ciudadana y Control Social (CPCCS), fue designado, por Decreto Ejecutivo N. ${ }^{\circ} 1734$, como el Organismo Público al cual, de acuerdo al nuevo marco institucional, corresponde dar continuidad a las funciones de lucha contra la corrupción que ejercía la extinta Comisión de Control Cívico de la Corrupción (arts. 207 y 208 de la Constitución Nacional). Asimismo, se constituye como Autoridad Central de la República del Ecuador para efectos de la aplicación de la Convención Interamericana contra la Corrupción (CICC). (Bouer, 2009, p. 58).

\section{Contraloría General del Estado}

Según dispone la Constitución de la República del Ecuador en sus artículos 204, 205 y 211, la Contraloría General del Estado es un organismo técnico dotado de personalidad jurídica y autonomía administrativa, financiera, presupuestaria y organizativa, dirigido y representado por el Contralor General del Estado, quien desempeñará sus funciones durante cinco años. El Contralor General es designado por el presidente de la República, a partir de una terna propuesta por el Congreso Nacional. (Bouer, 2009, p. 69) 


\section{Procuraduría General del Estado}

Este organismo público de control está dirigido y representado legamente por el procurador, con personería jurídica, patrimonio, autonomía administrativa, presupuestaria y financiera. Así mismo, el General del Estado, es nombrado por el Congreso Nacional. (Bouer, 2009, p. 78).

De esta manera se observar, que cada país, cuenta con legislación propia respecto al tema de la corrupción, cada una muy diferente de la otra debido a las diferentes concepciones que se tienen respecto a la corrupción. Sin embargo, a pesar de existir diferencias entre las legislaciones estudiadas, existen mayores similitudes. Las diferencias entre el derecho comparados estudiado es la aplicabilidad que tiene cada país con respecto a Bolivia, siendo importante ver la parte procedimental y ejecutorial de las leyes vigentes en nuestro país.

\section{CONCLUSIONES}

Se analizó las diferentes corrientes teóricas sobre la lucha contra la corrupción y se detalló las características de las fundaciones en el marco institucional boliviano. Por otro lado, se tomó como base la legislación boliviana en la cual se desenvolverá el observatorio y se comparó los marcos jurídicos de otros estados. Finalmente, se presentaron la estructura del acta de fundación y de estatutos para el observatorio de lucha contra la corrupción. Por lo que, se llegó a las siguientes conclusiones:

- Es necesario la implementación del Observatorio de lucha contra la corrupción para sumarse a la lucha contra ese mal mundial;

- Es necesario la participación ciudadana para luchar contra la corrupción y para ellos el Observatorio es una herramienta dentro de la sociedad;

- Con la implementación del Observatorio se pueden aportar datos y estadísticas sobre la corrupción en Bolivia.

- Se demostró mediante el Derecho Comparado que, si bien se considera que todas las legislaciones de las distintas naciones son completas y buenas en esencia, lo dificultoso es la aplicación y control.

- Se considera que dicho centro puede proveer de información real y verdadera que impulsaría la lucha contra la corrupción en el continente con mejores resultados 
REFERENCIAS

Bouer, D. (2009). Oficina Anticorrupción, Ministerio de Justicia, Seguridad y Derechos Humanos de la Nación: PNUD Argentina. pp. 30-34, 26,49-50,57-58, 68-69,78

Constitución Política del Estado de Bolivia. (2009). Bases Fundamentales de Derechos y Garantía Título IV, artículo 112

Gardiner, J. (2005). Defining corruption. Heidenheimer, Arnold \& Michael Johnston (editors) Political Corruption. Concepts \& Contexts - 3rd ed. New Jersey: Transaction Publishers, (2nd printin)
León. (1996). Aristóteles. Política y Económica, Facsímil de la edición de Zaragoza (1509). Universidad de León \& Cátedra San Isidoro, p. 301

Ministerio de Transparencia Institucional y Lucha Contra la Corrupción (2009). Informe Nacional de Avances, (Articulo 31, Reglamento Mesicic) La Paz, Bolivia

Moreno Ocanto, L. (1993). En defensa propia. Cómo salir de la Corrupción. Editorial Sudamericana. Buenos Aires, p. 103

Senturia, J.J. (1993). Encyclopedia of Social Sciences. Washington, Vol. VI, p. 45 